\title{
Do Currículo Mínimo às Diretrizes Curriculares: os estágios na formação do psicólogo
}

From Minimum Curriculum to Curricula Guidelines: the internship in psychologist's training

Del Currículo Mínimo a las Directrices Curriculares: las prácticas en la formación del psicólogo

\author{
Bruno de Morais Cury* \\ João Leite Ferreira Neto**
}

\begin{abstract}
Resumo
O objetivo deste artigo é investigar o processo de transformação dos estágios curriculares em Psicologia, desde o período de regulamentação da profissão, com o Currículo Mínimo, até a formalização das Diretrizes Curriculares Nacionais para os cursos de graduação em Psicologia, no período entre 1962 e 2004. Sua estratégia metodológica é a análise de documentos da área da Psicologia, considerados importantes nesse percurso. Nessa linha do tempo, foram trabalhados oito documentos governamentais ou de entidades representativas, selecionados por critérios históricos e de relevância. Concluiu-se que documentos regulatórios produzidos por "consensos", na verdade, são frutos de lutas e estratégias. Houve um longo e árduo percurso até a formulação do texto final das Diretrizes Curriculares. Nesse percurso, os estágios deixaram de ser pensados como espaços de aplicação de conhecimentos e ganharam autonomia própria, passando a ser reconhecidos como integradores das competências com base no enfrentamento de problemas concretos dos campos de atuação do psicólogo no Brasil.
\end{abstract}

Palavras-chave: Formação do psicólogo. Ensino da Psicologia. História da Psicologia.

\begin{abstract}
The objective of this paper is to investigate the process of curricular internship transformation in psychology from the period of regulation of the profession, with minimum curriculum, to the formalization of the National Curriculum Guidelines for undergraduate courses in Psychology, during the period between 1962 and 2004. Its methodological approach is the analysis of documents in the field of psychology, considered important in this journey. In this time line were worked on eight government documents or representative entities, selected by historical and relevance criteria. It was
\end{abstract}

\footnotetext{
* Mestre e bacharel em Psicologia pela Pontifícia Universidade Católica de Minas Gerais; gestor (coordenador) do curso de Psicologia da Univiçosa-Faviçosa; psicólogo. Endereço: Av. Maria de Paula Santana, no 3815 - Silvestre. Viçosa-MG, Brasil. CEP: 36570-000. Telefone: (31) 3899-8000. E-mail: brunomcury@yahoo.com.br.

** Professor do Programa de Pós-Graduação em Psicologia da Pontifícia Universidade Católica de Minas Gerais. Bolsista de produtividade CNPq. Endereço: Av. Itaú, no 525 - Dom Cabral, Belo Horizonte-MG, Brasil. CEP: 30535-012. Telefone: (31) 3319-4568. E-mail: jleite.bhe@terra.com.br.
} 
concluded that regulatory documents produced by "consensus" actually are the result of struggles and strategies. There was a long and arduous journey to the formulation into the final text of the Curriculum Guidelines. In that internships were no longer thought of as opportunities to apply knowledge, and they had gained autonomy, becoming recognized as integrators of skills from the concrete problems faced in psychologist practice.

Keywords: Psychologist education. Psychology education. History of Psychology.

\section{Resumen}

El objetivo de este trabajo es investigar el proceso de transformación de las prácticas curriculares en la Psicología, desde el período de reglamentación de la profesión, con el Currículo Mínimo, hasta la formalización de las Directrices Curriculares Nacionales para cursos de pregrado en Psicología, en el período comprendido entre 1962 y 2004. Su estrategia metodológica es el análisis de documentos del área de la Psicología que se considera importante en ese recorrido.

En esa línea de tiempo se trabajaron ocho documentos gubernamentales o de entidades representativas que fueron seleccionados por criterios históricos y de relevancia. Se concluyó que los documentos regulatorios producidos por "consensos", en realidad, eran fruto de luchas y estrategias. Hubo un largo y arduo trayectoria a la formulación del texto final de las Directrices Curriculares. En ese recorrido las prácticas dejaron de pensarse como espacios de aplicación de los conocimientos y ganaron autonomía propia, por lo que pasaron a ser reconocidos como integradores de las competencias a partir del enfrentamiento de problemas concretos de los campos de actuación del psicólogo.

Palabras clave: Formación del psicólogo. Enseñanza de Psicología. Historia de la Psicología.

\section{Introdução}

ouve considerável mudança na forma de se conceber os estágios curriculares na formação em Psicologia, gerada pela publicação em 2004 das Diretrizes Curriculares Nacionais (DCN) para os cursos de graduação. Este artigo pretende analisar, a partir de documentos que concorreram para a regulamentação da formação, como o debate em torno dos estágios nos cursos de Psicologia foi sendo construído. Seu objetivo, portanto, é traçar um desenho 
do processo de mudança na compreensão dos estágios curriculares, desde o período de regulamentação da profissão até a aprovação das DCN para os cursos de graduação em Psicologia, com base na análise de documentos da área.

Apesar da relevância dos estágios na formação, há uma carência dessa discussão na literatura, principalmente em sua ligação com os cursos de Psicologia. Mesmo os autores que tratam da formação do psicólogo, em geral apenas mencionam os estágios, sem tomá-los como foco do estudo (Gomes, 1996; Rocha Junior, 1999; Ferreira Neto, 2010). Esse quadro de poucas investigaçôes voltadas ao tema justifica a importância do estudo aqui apresentado.

De acordo com o Conselho Nacional de Educação (CNE), o conceito de estágio supervisionado consolidou-se, historicamente, no Brasil, ligado ao conjunto das Leis Orgânicas do Ensino Profissional, definidas no período de 1942-1946 (Brasil, 2003). Nessa época, os estágios supervisionados eram vistos como "etapa preparatória" para a ocupação de postos de trabalho. Representavam oportunidade aos alunos na formação industrial, comercial ou agrícola de conhecerem, in loco, aquilo que lhes era ensinado nas escolas. A ênfase estava colocada no estágio como campo de demonstração do ensino acadêmico.

Foi na década de 1970, com a implantação da Lei Federal no 5.692/71 (Lei n. 5.692, 1971), que os estágios curriculares supervisionados ganharam força e cresceram em importância. A partir daí, passou-se a considerar o estágio supervisionado como obrigatório para as habilitações profissionais técnicas dos setores primário e secundário da economia, bem como para a área de saúde.

Uma década após, o artigo $2^{\circ}$ do Decreto no 87.497 - que regulamenta o estágio de estudante de estabelecimentos de ensino superior - definiu como estágio curricular: "as atividades de aprendizagem social, profissional e cultural, proporcionadas ao estudante pela participação em situaçôes reais de vida e trabalho em seu meio, sendo realizadas na comunidade em geral ou junto a pessoas jurídicas de direito público ou privado." (Decreto no 87.497, 1982).

Temos assim uma ampliação do entendimento da função e escopo dos estágios profissionais. Estes agora não são tomados apenas como campo de ilustração do que é aprendido no contexto da sala de aula, mas também como campo de aprendizagem que possui elementos próprios e autônomos em relação ao ensino formal.

As concepções sobre os estágios curriculares em Psicologia sofreram diversas alterações nas regulamentações ao longo do tempo até se chegar à publicação definitiva das DCN em maio de 2004. Como veremos adiante, passou-se progressivamente de um centralismo nos conteúdos transmitidos em sala de aula, 
tendo os estágios como complemento que "exemplificava" o que foi ensinado, para uma relação mais interativa entre teoria e prática ampliando-se a presença e as possibilidades formativas dos estágios.

\section{Método}

Para se pensar nos estágios nos cursos de graduação em Psicologia é importante analisar como eles foram formados no Brasil, desde a regulamentação da profissão, em 1962, até a publicação do texto final das DNC em 2004. Questôes sobre o que é o estágio, a que se presta e qual sua trajetória histórica são essenciais a esta pesquisa. Analisar os documentos mais importantes da formação psicológica, que engloba a evolução dos estágios, permite tecer suas configurações temporais.

O conjunto desses documentos consultados encontra-se no site da Associação Brasileira de Ensino de Psicologia (ABEP). ${ }^{1}$ Encontra-se neste site um arquivo de "linha do tempo da psicologia" contendo 61 documentos. Alguns são apenas mencionados, mas a maioria possui versão integral disponível. Essa "linha" vai de 1932 (o primeiro projeto de curso de Psicologia) a 2011(versão final das Diretrizes Curriculares, que agrega à Resolução de 2004 a normatização para a Licenciatura em Psicologia). Há uma concentração dos documentos no período entre 1997 a 2004, período quando foi desencadeada a discussão em torno das Diretrizes Curriculares Nacionais, o que indica a centralidade de sua intervenção no que tange à formação em Psicologia no Brasil.

Cellard (2008) sugere que o pesquisador que faz uso de documentos deve "localizar os textos pertinentes e avaliar sua credibilidade, assim como, a sua representatividade." (p. 296). Para este estudo foram utilizados alguns critérios de escolha dos documentos que seriam analisados, relativos tanto ao aspecto histórico, quanto à importância política e estratégia do mesmo. No aspecto histórico, o primeiro critério foi excluir os documentos anteriores ao Currículo Mínimo, de 1962, por serem anteriores à regulamentação da profissão de Psicologia no País. Restaram, a partir deste corte, 46 documentos.

Quanto ao quesito relevância, privilegiamos os documentos em torno do Currículo Mínimo e do debate em torno das Diretrizes. Buscamos também, de modo mais incisivo, documentos que mencionavam os estágios na formação, foco maior desta pesquisa. Outro critério adotado foi a não restrição a documentos normativos oriundos do Ministério da Educação, optando-se pela inclusão de documentos produzidos por variadas entidades da Psicologia, que foram protagonistas nesse processo de mudança das condições da formação. Incluímos, assim, três Cartas produzidas pelas entidades da área e indicadas no quadro 1,

\footnotetext{
${ }^{1}$ Disponível em: http://www.abepsi.org.br/portal/?page_id=75.
} 
que expunham as disputas em jogo durante a elaboração das Diretrizes, mesmo quando não focadas diretamente na temática dos estágios.

Esses critérios de relevância ocasionaram uma redução dos 46 documentos para 8, considerados pertinentes e com representatividade, em relação aos objetivos da pesquisa.

O quadro 1 aponta os referidos documentos que foram trabalhados neste artigo, indicados pelo número, ano, documento (título), origem e eixos básicos dos mesmos, especialmente no que diz respeito aos estágios.

Quadro 1 - Documentos referentes à formação do psicólogo

\begin{tabular}{|c|c|c|c|c|}
\hline $\mathbf{N}^{\circ}$ & Ano & Documento (título) & Origem & Eixo básico \\
\hline 1 & 1962 & $\begin{array}{l}\text { Lei } 4.119 \text { de } 27 \text { de } \\
\text { agosto de } 1962 \text { - } \\
\text { Regulamenta a profissão }\end{array}$ & Lei & $\begin{array}{l}\text { Os estágios e observações } \\
\text { práticas poderão ser } \\
\text { realizados em outras } \\
\text { Instituições. }\end{array}$ \\
\hline 2 & 1962 & $\begin{array}{l}\text { Resolução de } 19 / \\
12 / 1962 \text { do CFE - fixa o } \\
\text { currículo mínimo para } \\
\text { os cursos de Psicologia }\end{array}$ & $\begin{array}{l}\text { Resolução do } \\
\text { CFE }\end{array}$ & $\begin{array}{l}\text { Estágios obrigatórios como } \\
\text { um período de treinamento } \\
\text { prático sob essa forma, } \\
\text { supervisionados. }\end{array}$ \\
\hline 3 & 1962 & $\begin{array}{l}\text { Parecer } n^{\circ} 403 / 62 \text { do } \\
\text { CFE, aprovado em } \\
\text { 19/12/1962 - sobre o } \\
\text { currículo mínimo dos } \\
\text { cursos de Psicologia }\end{array}$ & Parecer do CFE & $\begin{array}{l}\text { A formação terá de } \\
\text { completar-se com um } \\
\text { estágio que se desenvolva } \\
\text { em situação real com } \\
\text { ao menos } 500 \text { horas de } \\
\text { atividades supervisionadas. }\end{array}$ \\
\hline 4 & 1992 & Carta de Serra Negra & $\begin{array}{l}\text { Doc. CFP e } \\
\text { Instituições de } \\
\text { Ensino Superior } \\
\text { em Psicologia }\end{array}$ & $\begin{array}{l}\text { O curso deve oferecer } \\
\text { campos de estágio, } \\
\text { além de um sistema } \\
\text { de acompanhamento e } \\
\text { avaliação nos locais onde } \\
\text { são realizados. }\end{array}$ \\
\hline 5 & 1995 & $\begin{array}{l}\text { A formação } \\
\text { em Psicologia: } \\
\text { contribuições para } \\
\text { reestruturação } \\
\text { curricular e avaliação } \\
\text { dos cursos }\end{array}$ & $\begin{array}{l}\text { Comissão de } \\
\text { especialistas } \\
\text { MEC/SESU }\end{array}$ & $\begin{array}{l}\text { Estágios definidos: "Permitir } \\
\text { uma efetiva integração } \\
\text { teoria-prática". Distribuição } \\
\text { das atividades práticas } \\
\text { durante todo o curso. }\end{array}$ \\
\hline 6 & 2001 & Carta ao ministro & ANPEPP & $\begin{array}{l}\text { Crítica à versão de } 2001 \text { das } \\
\text { Diretrizes }\end{array}$ \\
\hline 7 & 2001 & $\begin{array}{l}\text { Carta aberta à } \\
\text { população }\end{array}$ & $\begin{array}{l}\text { CFP, ABEP e } \\
\text { Conep }\end{array}$ & $\begin{array}{l}\text { Crítica à versão de } 2001 \text { das } \\
\text { Diretrizes }\end{array}$ \\
\hline 8 & 2004 & $\begin{array}{l}\text { Parecer } n^{\circ} 0062 / 2004 \\
\text { - CNE - Diretrizes } \\
\text { Curriculares. }\end{array}$ & Parecer do CNE & $\begin{array}{l}\text { Define } 15 \% \text { da carga horária } \\
\text { total do Curso aos estágios } \\
\text { curriculares. }\end{array}$ \\
\hline
\end{tabular}

Fonte: dados da pesquisa. 
A análise de documentos envolve não somente uma hermenêutica do texto, mas necessita de um diálogo com as suas condições de produção (autoria, contexto de produção, função, etc.). Existem movimentos analíticos que são indispensáveis para a feitura de um estudo pertinente de documentos, como sugere o cientista social Howard Becker:

O observador tem que examinar cuidadosamente como os documentos com que ele trabalha foram criados; por quem, seguindo que procedimentos, e para que propósitos? Pois é claro que os documentos não podem ser aceitos pelo seu valor de face, mas têm que ser interpretados à luz de tais considerações (1999, p. 122-123).

\section{Resultados e discussão}

Consoante ao desenho de organização das fontes consultadas, trabalhamos os documentos dividindo sua linha do tempo em três períodos. No primeiro, que chamamos "inaugural", trabalhamos os três primeiros documentos que normatizaram a profissão e a formação, todos do ano de 1962. No segundo, "Construindo consensos", estudamos dois documentos da década de 1990, que apresentam consolidados dos extensos debates transcorridos nas décadas de 1970 e 1980, propondo princípios e diretrizes que reordenam a mudança curricular. Finalmente, no período que intitulamos "Diretrizes Curriculares: embates e definições" discutirão os documentos referentes ao debate em torno das Diretrizes Curriculares e sua redação final. Em cada momento agregamos dados históricos que permitam uma visão do contexto, por vezes tenso, que permeou a produção desses documentos, de modo a possibilitar uma perspectiva mais complexa do processo de construção das definiçõos sobre os estágios no campo da formação dos psicólogos.

\section{Período inaugural}

Os dois primeiros documentos, datados de 1962, tratam da regulamentação da Psicologia como profissão no Brasil e do Currículo Mínimo dos cursos de Psicologia; mesmo que o primeiro deles, da Pontifícia Universidade Católica do Rio de Janeiro, já houvesse iniciado suas atividades em 1953. A profissão foi regulamentada prevendo-se três terminalidades, a de bacharel, a de licenciado e a de formação de psicólogo, sendo que apenas na última era permitido o exercício pleno da profissão.

A respeito das condições para funcionamento do curso, a Lei 4.119 preconiza que os cursos deveriam oferecer serviços supervisionados pelos professores nas três áreas de atuação do psicólogo, ou seja, clínica, educação e trabalho. Além disso, 
os estágios poderiam ser realizados em outras instituições locais (Lei no 4.119, 1962). Após essa Lei, de 27/08/1962, vários documentos foram elaborados a fim de tratar e sistematizar questôes práticas, sendo os mais importantes a Resolução que cria o Currículo Mínimo (Brasil, 1962b) e o Parecer que a ela se refere (Parecer n. 403/62 do CFE, 1962).

A Resolução do Conselho Federal de Educação (CFE) estabeleceu os estágios como obrigatórios para a obtenção do grau formação de psicólogo, definindoos como um período de treinamento prático supervisionado (Art. $2^{\circ}$, alínea b), que deveria ocorrer no último ano do curso, quando se estabelecia, para além do bacharelado, a formação do psicólogo (Brasil, 1962). Ao se tornarem os estágios obrigatórios apenas na terminalidade de "formação do psicólogo", que tinha um ano a mais de duração em relação ao "bacharelado em psicologia", indicava-se sua realização na etapa final do curso.

O terceiro documento a ser realçado deste período inaugural, o parecer $\mathrm{n}^{\circ}$ 403/62, aponta:

O trabalho do Psicólogo - é sempre, no fundo, uma tarefa de educação, ou reeducação que se vale de técnicas próprias cujo dominio é impossivel sem o devido treinamento prático. Assim, tal como ocorre no ensino médico e agora se exige para qualquer modalidade, de licenciatura, a sua formação teórico experimental terá de completar-se com um estágio, que se desenvolva em situação real, ao longo de pelo menos 500 horas de atividades - e obedeça à imediata supervisãa dos órgãos por ela responsáveis (Parecer n. $403 / 62$ do CFE, 1962, p. 2).

Assim, esse Parecer fixou a carga horária mínima de estágios obrigatórios supervisionados, além de haver destacado a importância dos estágios para a formação dos psicólogos. Em suma, temos nesse período inaugural a oficialização do estágio como quesito essencial para a formação plena do psicólogo, que deveria ser realizado nos serviços próprios da instituição de ensino superior e facultado em outros espaços, sempre sob supervisão. O desenho que temos nesses documentos reforça a ideia de "treinamento prático" de habilidades que não poderiam ser plenamente aprendidas em sala de aula. Além disso, pressupóe que certo saber já estabelecido servirá como fundamento para essas atividades práticas.

Concordamos com a avaliação de Gomes (1996) sobre a tradição curricular inaugurada em 1962 na Psicologia: "[o] Currículo para os cursos de Psicologia proposto em 1962 refletia a lógica de uma formação que vai dos fundamentos e da experimentação para os estágios profissionais e para a aplicação.” (p. 40). Essa perspectiva que caminhava da fundamentação à aplicação, tomava os saberes como produção definida, por vezes definitiva, e embasamento suficiente para o desenvolvimento das formas de atuação, entendidas como aplicação dos 
fundamentos teóricos. Esse modelo de currículo perdurou em muitos cursos até o início das mudanças desencadeadas pelas DCN. Contudo, como veremos adiante, houve um crescente aumento de insatisfação em relação a esse desenho entre docentes e discentes.

O primeiro Currículo Mínimo oficial, fixado pelo CFE, em 1962, expressava uma visão daquilo que se ensinava nos cursos iniciantes de Psicologia e era exercido na prática profissional em Psicologia, feita, à época, principalmente por pedagogos. Segundo Rocha Júnior (1999), desde então, boa parte dos psicólogos sempre se mostraram incomodados quanto à própria formação.

\section{Construindo consensos}

Nas décadas seguintes à regulamentação da Psicologia como profissão viuse uma de suas áreas de atuação ganhar hegemonia nos currículos: a clínica. A escassez de profissionais face à demanda de uma classe média que ascendia com a industrialização do país, tornou essa uma atividade altamente lucrativa. Isso acarretou uma série de distorções na formação que só vieram à luz com clareza no período de redemocratização, quando a Psicologia passou a ser criticada como uma profissão a serviço das elites e de seus profissionais serem vistos como "guardiōes da ordem" (Coimbra, 1995; Ferreira Neto, 2010). O detalhamento desse processo foge ao escopo deste artigo, mas estão detalhados nos dois textos mencionados.

A literatura da segunda metade da década de 1970 reagiu a esse estado de coisas apontando a necessidade de a Psicologia rever seus rumos. Um estudo pioneiro da professora Sílvia Leser de Mello Pereira (1975) antecipou os desdobramentos desse processo. A hipótese da autora era que o encontro com outras dimensões do fazer psicológico, distante da demanda dos neuróticos da classe média nos consultórios particulares, seria um acontecimento com efeitos irreversíveis no contexto da formação. Os conteúdos teóricos e técnicos pretensamente universalizantes, mas de fato produzidos a partir de modos de subjetivação produzidos por condições sócio-históricas específicas, sofreriam um forte abalo. A autora afirmava que objeto de intervenção do psicólogo é uma "máquina que tem seu mecanismo, em grande parte, determinado pela sociedade." (Pereira, 1975, p. 18).

Em outros artigos escritos no mesmo período, Botomé (1979) questionava o custo do tratamento clínico num País pobre, e Weber e Carraher (1982) criticavam a formação "livresca" em Psicologia que tornava os estudantes meros consumidores de conhecimento já elaborado no exterior, descontextualizado da realidade brasileira. Eram muitas as vozes que se levantavam dentro e fora da 
academia pondo em xeque o modelo de formação em Psicologia (Ferreira Neto, 2010).

A partir da década de 1980, com a finalidade de discutir a formação e o exercício profissional em Psicologia, o Conselho Federal de Psicologia (CFP) promoveu uma série de atividades. Em 1983, iniciou amplo debate sobre problemas no exercício da profissão e necessidade de reformulação do currículo em Psicologia. Interessado em definir o perfil do psicólogo brasileiro e com o apoio de autorespesquisadores, trabalhou-se a questão da formação do psicólogo no Brasil com estudos que geraram vários estudos e publicaçôes (CFP, 1994).

Temos assim o surgimento de um importante ator institucional protagonista, o CFP, desde então, na formulação de sugestôes e na realização de enfrentamentos para pensar e intervir sobre os rumos da formação. Os dois documentos escolhidos retratam o final dessa etapa, na qual, após críticas e debates, a área da Psicologia começou a construir alguns consensos.

O primeiro deles, intitulado Carta de Serra Negra (CFP, 1992), foi elaborado num evento que envolveu a participação de 98 das 103 instituições de ensino superior do país que ofertavam cursos de Psicologia à época. Foi um marco divisor de águas, tanto em termos políticos, pela mobilização que provocou, quanto em termos do conteúdo das propostas (Bernardes, 2004), o que realça a importância desse documento.

Não é somente um documento importante pelo seu conteúdo, mas também pelas circunstâncias em que foi produzido. Além da forte presença e articulação entre as entidades (por meio do Sistema Conselho), há uma grande produção da Comissão de Especialistas do MEC/SESU, no que tange às novas discussões sobre as reformas curriculares (Bernardes, 2004, p. 109).

A proposta colocada envolvia a elaboração de princípios que deveriam nortear a formação no currículo e nos estágios. Havia forte ênfase sobre compromisso ético da Psicologia com a realidade social. Os princípios expostos na Carta de Serra Negra defendiam um redirecionamento na formação do psicólogo brasileiro no sentido de enfatizar a consciência política de cidadania, o compromisso com a realidade social e a qualidade de vida. Além disso, enfatizavam o desenvolvimento da construção do conhecimento por meio de uma postura crítica, investigadora e criativa, fomentando a pesquisa num contexto de ação-reflexão-ação, bem como viabilizando a produção técnico-científica. Apoiavam também o estabelecimento de uma formação básica pluralista fundamentada em discussões epistemológicas, éticas e políticas, visando à consolidação de práticas profissionais, conforme a realidade sociocultural, adequando o currículo pleno de instituição formadora ao seu contexto regional. Afirmava que o conhecimento deveria primar pelo senso crítico a fim de privilegiar também o estudo e o debate sobre os saberes 
teóricos mais abrangentes da pesquisa científica, saberes que possibilitassem a compreensão da realidade local.

Fica clara, nesse documento, uma maior preocupação sobre a função social do psicólogo a partir da sua prática, o que realçava a importância dos estágios curriculares supervisionados. Nesse quesito, o documento sugeria que os cursos deveriam oferecer campos de estágio que contemplassem a prática de variadas concepções em Psicologia, além de manter um sistema de acompanhamento e avaliação continuada dos estágios nos locais onde eram desenvolvidos, buscando verificar sua adequação às necessidades de formação do aluno. De acordo com Francisco e Bastos (1992), esse encontro ratificou a necessidade imperiosa de mudanças profundas no processo de formação, muitas das quais deveriam envolver reformas curriculares.

O segundo documento desse período, elaborado pela Comissão de Especialistas de Ensino de Psicologia apresentava 10 diretrizes gerais para a formação do psicólogo visando à reestruturação curricular dos cursos, com base nas pesquisas realizadas pelo CFP, em estudos feitos pelas instituições formadoras e em teses produzidas em congressos da área (Borges, Bastos \& Khouri, 1995). Apoiava-se em pontos que pareciam mais consensuais, mesmo reconhecendo não haver uma unanimidade. De qualquer modo, percebe-se que, naquele momento, havia uma confluência, mesmo sem unanimidade, de diversas propostas de mudanças na formação, num esforço para se construir, com base em extensos debates, algumas direçōes consensuais.

O documento trazia uma construção consistente baseada na literatura sobre a formação, com linhas argumentativas bem construídas, fruto do trabalho de três professores pesquisadores, dois de universidades públicas e um de universidade confessional privada. Retomava o conhecido diagnóstico de que havia uma formação fragmentada, excessivamente dominada pela área clínica com enfoque psicanalítico, que não contemplava, de modo adequado, a pluralidade da Psicologia. Os estágios eram discutidos na diretriz VI e preconizava-se que deveriam "permitir uma efetiva integração teoria-prática". Os autores afirmavam, com base em pesquisas realizadas, que os psicólogos apontavam como um aspecto negativo de sua formação a "carência de atividades práticas", e se queixavam do "verbalismo" onipresente na formação. Em função disso o texto sugere como estratégia uma "gradação em que o aluno é exposto às situações concretas do exercício profissional.” (Borges et al., 1995, p. 20), a partir de diversos níveis de estágios. Considera importante uma distribuição das atividades práticas durante todo o curso e não somente nos períodos finais, como era a tendência até então. 
Em síntese, temos nesse segundo período a construção de consensos tanto sobre a formação em geral, quanto sobre os estágios em particular. Em relação aos últimos foram propostas mudanças quantitativas e qualitativas. Quantitativamente há uma proposta de aumento da carga horária de estágios durante a graduação, além de sua alocação por todo o currículo, com níveis gradativos de complexidade, e não se restringindo mais apenas às etapas finais dos cursos, o que seria definitivamente implantado em 2004 pelas Diretrizes Curriculares. Do ponto de vista qualitativo, ambos os documentos sugerem a ampliação da diversidade de oferta de outras concepções de Psicologia, tanto nas disciplinas quanto nos estágios, visando superar a centralidade da formação em clínica.

Em suma, o conjunto de propostas desenvolvidas nesse período influenciou, de modo decisivo, o cenário do debate sobre a formação, contribuindo para a formalização do desenho final da mudança curricular estrutural, que ocorreu em 2004, com a indução do MEC, promovendo a elaboração de Diretrizes Curriculares Nacionais para os cursos de graduação em Psicologia.

\section{Diretrizes Curriculares Nacionais: embates e definições}

Em 1997 o MEC desencadeou o processo de formulação das novas "Diretrizes Curriculares Nacionais para os cursos de graduação" no País, visando atender às exigências da LDB. Cada área, liderada por uma Comissão de Especialistas, após amplo debate, deveria definir um novo modelo para a formação na graduação. A principal mudança estrutural trazida pelas Diretrizes, não somente para o nível superior, mas também para o nível fundamental e médio, foi substituir a tradição formativa fundamentada na transmissão de conteúdos nas disciplinas, para uma formação baseada em "competências e habilidades".

Uma definição operacional de competência, inspirada na obra do sociólogo Perrenoud, a desenha como a capacidade de agir eficazmente em diferentes situações, apoiando-se em conhecimentos e mobilizando variados recursos (Silva, 2008). Assim, o centro da formação se transferiria da transmissão e reprodução de conteúdos, para a produção de capacidades de atuação em diferentes contextos. Envolve, portanto, uma mudança da cultura formativa. Sabemos que mudanças na cultura não se dão de modo imediato, mas demandam esforços articulados e persistentes. Essa mudança implica em transformações na lógica na formação, ainda não inteiramente apreendida. Ressalta-se que os atuais docentes foram, em grande parte, formados no modelo conteudista anterior, e por isso tendem a pensar as reformas curriculares ainda tendo como foco os conteúdos na grade de disciplinas ${ }^{2}$ Por conseguinte, a definição das DCN demandará ainda terá um

${ }^{2} \mathrm{Na}$ experiência de trabalho de um dos autores com reforma e avaliação de reforma curricular, percebeu-se como vários 
longo percurso de debate e aprofundamento sobre o sentido da formação por competências e habilidades.

O processo da construção final das DCN foi altamente controverso. Muitos encontros, muitas idas e vindas, avanços e recuos, consensos e dissensos (Carvalho, 2002). Analisaremos a seguir dois documentos no formato de cartas, produzidos por entidades da área, que explicitam as tensôes e controvérsias que antecederam a redação final de texto da Resolução.

Essas cartas, assinadas por entidades distintas, configuram-se como reações contra a primeira versão das Diretrizes aprovadas pelo CNE, que aguardava a homologação do Ministro da Educação Paulo Renato. Diversas entidades se manifestaram contrárias à homologação do texto tal como estava redigido, exigindo alterações no desenho da proposta.

A primeira carta era assinada pela Associação Brasileira de Pesquisa e PósGraduação em Psicologia (ANPEPP), endereçada ao Ministro da Educação, e ressaltava que o documento com a proposta das Diretrizes não respeitou o conteúdo de texto anterior, construído de modo mais consensual e democrático por variados grupos e entidades (Associação Nacional de Pesquisa e PósGraduação em Psicologia [ANPEPP], 2001). Criticava em especial três ausências e um acréscimo. As ausências de parâmetros definidores da carga horária mínima para os cursos, da delimitação de número máximo de alunos por supervisor de estágio, das atribuiçôes do psicólogo na educação. Além disso, criticava novas inserçôes que passavam a caracterizar o psicólogo como um profissional exclusivo da área da saúde.

A segunda carta, assinada pelo CFP, pela ABEP - entidade criada no decurso dos debates em torno das Diretrizes - e pelo Conselho Nacional das Entidades estudantis em Psicologia (Conep), era endereçada à população em geral (Associação Brasileira de Ensino de Psicologia; Conselho Federal de Psicologia \& Conselho Nacional das Entidades Estudantis em Psicologia, 2001). Sua crítica incidia sobre três aspectos: recusava o atrelamento da Psicologia à área da saúde; censurava a existência de três perfis profissionais nos cursos, pelo entendimento de que geraria uma separação entre pesquisa e prática profissional; e rejeitava a proposta de ênfases curriculares para os cursos, por considerarem ser contrária ao consenso construído na área que defendia uma formação generalista.

Ambas as cartas tinham em comum a recusa do atrelamento da Psicologia à área da saúde e a denúncia dos riscos de que certas definiçôes (como as ênfases) ou indefinições (como a falta de parâmetros de carga horária e de número máximo

docentes se ressentem quando parte do conteúdo anterior é substituído por atividades práticas de formação, em decorrência do aumento da carga horária dos estágios estabelecida pelas Diretrizes. Tal situação é muitas vezes entendida na ótica de uma perda do que julgam ser mais essencial, dentro de uma perspectiva de ensino ainda centrada na transmissão de conteúdos. 
de alunos por supervisor) poderiam ser usadas por empresários da educação para reduzirem seus custos em detrimento da qualidade da formação.

Este último é um tema crucial, pouco explorado pela literatura. $\mathrm{Na}$ medida em que a maior parte dos formandos em Psicologia no Brasil é oriunda de instituições privadas (Bastos \& Gondim, 2010), a realidade do mercado privado do ensino superior carece de uma problematização mais incisiva. Isso ficou agravado na medida em que diferentes Comissões de Especialistas eram, em geral, compostas por docentes de instituições públicas e em menor número de privadas confessionais. Assim, o grande segmento, plenamente privado, deixava de comparecer formalmente à análise e ao debate sobre a formação, ocasionando em decorrência disso que os parâmetros mais estudados proviessem dos perfis institucionais próprios de universidades públicas, mesmo que as mesmas, quantitativamente, fossem minoritárias na formação de psicólogos no Brasil. Como o segmento privado está mais diretamente atrelado às condições de mercado, costuma pautar suas decisões políticas e de gestão pelo mesmo, muitas vezes em detrimento das questôes acadêmicas e pedagógicas. Assim, a definição da composição das Comissões do MEC/SESU revelou-se restritiva, gerando consequências indesejáveis no conjunto da formação. Por um lado, regulamentava-se pouco o setor privado de ensino superior (como foi denunciado nas duas cartas analisadas) uma vez que os parâmetros de discussão eram pautados pelas experiências das universidades públicas. Por outro, não se discutia a formação em sua relação com o mercado, distanciando-a assim de parte de suas condiçôes concretas e materiais de funcionamento.

Em função do embate ocorrido em 2001, houve um atraso significativo na aprovação do documento final das Diretrizes. Em 3 de julho de 2002, atendendo à ordem do Ministro da Educação, o Secretário da SESU devolveu o parecer 072/2002 ao CNE, que havia sido aprovado em 20 de fevereiro de 2002. Um documento consensual só veio à luz em fevereiro de 2004. Em relação às reivindicações colocadas através das Cartas de 2001, apenas duas não foram contempladas: os pedidos de retirada das ênfases curriculares e de delimitação de número máximo de alunos por supervisor de estágio.

Sobre os estágios supervisionados, depois de muitas variações dos documentos anteriores, a carga horária foi definida, mantendo-se a estrutura original da versão de 1999 no que tange à divisão entre estágio básico e específico, aumentado sua proporção de $10 \%$ para $15 \%$ da carga horária total do curso, o que representou crescimento proporcional de 50\% dos estágios em relação à proposta de 1999.

O artigo 19 lista um total de dez atividades formativas como compondo necessariamente a carga horária curricular. Esta lista inicia-se com a menção 
às aulas expositivas e encerrava-se com os estágios, passando por exercícios em laboratórios, atividades de pesquisa, de extensão, monitorias, visitas técnicas, entre outras. Reafirma-se assim a necessária diversidade das atividades formativas possíveis para efetivar uma formação de qualidade. Delineia-se um currículo não mais fundamentado em conteúdos disciplinares, mas em um conjunto variado de atividades formativas.

Na menção aos estágios da lista das 10 atividades formativas, estes são definidos como "Práticas integrativas voltadas para o desenvolvimento de habilidades e competências em situações de complexidade variada, representativas do efetivo exercício profissional" (Resolução no 8, 2004). Esta definição agrega um elemento inovador em relação ao histórico das discussões e documentos anteriores: integrar competências, habilidades e conhecimentos em situações de atuação. Podemos inferir disso o fato da pluralidade, por vezes antagonista, que compõe a Psicologia, não encontrar possibilidade integrativa no verbalismo das exposições teóricas, mas sim no manejo de situações nas atividades práticas integrando nesse movimento o diálogo entre teorias e práticas. Aqui não se faz um juízo de valor da supremacia das atividades práticas sobre as atividades teóricas na formação. Ao contrário, reconhecendo-se a importância de ambas, afirma-se que desempenham funções diferentes. Entretanto, a mesma definição poderia ser aplicada às atividades de sala de aula. Nessa nova lógica, estas também deveriam ser instadas ao compromisso de promoção de um "saber em uso" mediante discussões reflexivas e situacionais, nas quais conhecimentos dialogam e problematizam com realidades e experiências atuais, e não apenas com os contextos de produção das teorias e metodologias desenvolvidas.

Os estágios supervisionados ainda são definidos de modo operacional no art. 20 como um "conjunto de atividades de formação, programados e diretamente supervisionados por membros do corpo docente da instituição formadora e procuram assegurar a consolidação e a articulação das competências estabelecidas." (Resolução no 8, 2004). Devem assegurar o contato com "situações, contextos e instituições", concretizando conhecimentos, competências e habilidades "em ações profissionais", além de serem distribuídos ao longo do curso (p. 11).

Outro elemento importante é a demarcação da singularidade e da autonomia com a qual os estágios passam a ser pensados. Não se visa mais aplicar nos estágios o conhecimento transmitido em sala de aula, mas reconhecer que tanto sala de aula quanto estágios são espaços que permitem, ou mesmo exigem, o desenvolvimento de práticas integrativas num diálogo permanente entre teoria e prática. 


\section{Considerações finais}

Como ficou indicado no decorrer deste estudo, documentos regulatórios são produzidos por negociaçõos resultantes de lutas e estratégias. Seu formato final não é feito apenas por muitas mãos, mas também por discussões, embates, impasses. Assim, a pesquisa documental não deve tomá-los como peças acabadas e definitivas, mas realçar a arquitetura do embate entre as forças, seu contexto histórico e institucional e, sobretudo, seu caráter contingencial fruto de uma negociação em torno do que era possível, em dado momento históricoinstitucional. São relaçôes de poder que decidem um ordenamento discursivo com impactos em certo campo de práticas. Como avalia Foucault discorrendo sobre a ordem do discurso: "O discurso não é simplesmente aquilo que traduz as lutas ou sistemas de dominação, mas aquilo por que, pelo que se luta, o poder do qual queremos nos apoderar" (Foucault, 1996, p. 10).

A análise que fizemos da trajetória da Psicologia em relação aos estágios, do Currículo Mínimo às Diretrizes Curriculares, atesta visíveis mudanças e inovaçóes. Contudo, o delineamento histórico esboçado neste artigo não representa uma adesão dos autores à forma atual do Documento que rege nossa formação. No aspecto geral as DCN não enfrentaram diretamente o centralismo verbalista da sala de aula na tradição conteudista da formação em Psicologia, nem problematizaram a contento qual a relação dessa forte tradição com as demais atividades práticas desenvolvidas nos cursos. Isso possibilita que cursos efetuem mudanças curriculares utilizando-se do vocabulário das competências e habilidades, mas sem apreender as consequências dessa lógica em relação às práticas formativas.

Evidentemente, a tensão histórica advinda da relação entre teoria e prática persiste. Em determinados contextos a teoria ainda permanece, para vários docentes que se formaram no modelo do Currículo Mínimo, como fundamento da prática. Em contrapartida, especialmente nos cursos particulares que historicamente investem pouco em pesquisa, corre-se atualmente o risco da construção de modos de ação operativos e pragmáticos, sem o necessário apuro conceitual. Essa ênfase desequilibrada no "como fazer" pode se configurar como um empecilho para a profissão trazer contribuições de fato relevantes e que produzam mudanças no estado de coisas, operando assim as condições para a atuação de qualidade e inovadora. Entendemos que, nesse deslocamento dos conteúdos para as competências, o objetivo não deve ser abandonar a teoria como fundamento, em favor da atividade prática, como seu sucedâneo. É importante entendermos o enlaçamento necessário entre teoria e prática como um "fundamento em movimento" (Ferreira Neto, 2011, p. 45), favorecendo a sinergia do encontro entre essas duas dimensões da prática acadêmica na direção do aperfeiçoamento da formação. 
Outro elemento que preocupa são as ênfases curriculares, que surgiram numa proposta colocada inicialmente pelo MEC/SESU, visando a permitir a flexibilização curricular. Contudo, a maioria das outras áreas de graduação superior optou pela sua não adoção. A Psicologia fez a opção da minoria dos cursos de graduação que adotaram as ênfases curriculares. Já que foi essa foi nossa escolha em 2004, passados dez anos é tempo de avaliarmos suas consequências. Carecemos de estudos sobre a implantação das reformas curriculares dos cursos pelo País, a partir da aprovação das DCN, de modo a entendermos o quanto efetivamente se avançou e o quanto se perdeu com a institucionalização das ênfases curriculares. $\mathrm{O}$ tema das ênfases curriculares ainda gera controvérsias tanto sobre sua necessidade, quanto sobre como deve se dar sua operacionalização.

No que se refere aos estágios, reconhecemos avanços na atual formulação presente nas Diretrizes. Eles deixaram de ser pensados como espaços de aplicação de conhecimentos oferecidos no contexto de sala de aula. Reafirma-se sua importância na formação e sua função de integrar competências, habilidades e conhecimentos. Ao serem colocados diante de situações concretas de atuação os estudantes são convocados a uma atividade que não pode ser plenamente atrelada a um conteúdo disciplinar específico. Pelo contrário, nessa situação, eles devem articular conhecimentos, competências e habilidades ao agir no enfrentamento de problemas concretos advindos do seu campo de atuação ou de investigação.

\section{Referências}

Associação Brasileira de Ensino de Psicologia; Conselho Federal de Psicologia \& Conselho Nacional das Entidades Estudantis em Psicologia (2001). Carta aberta à população do CFP, ABEP e CONEP. Brasília: ABEP. Recuperado a partir de http://www.abepsi.org.br/portal/wp-content/uploads/2011/07/2001cartaabertaapopulacaodocfp.pdf

Associação Nacional de Pesquisa e Pós-Graduação em Psicologia (2001). Carta da ANPEPP ao ministro. Vitória: ANPEPP.

Bastos, A. V. B. \& Gondim, S. M. G. (Org.) (2010). O trabalho do psicólogo no Brasil. Porto Alegre: Artmed.

Becker, H. (1999). Observação social e estudos de caso sociais. In H. Becker. Métodos de pesquisa em ciências sociais. (pp. 117-133). São Paulo: Hucitec.

Bernardes, J. S. (2004). O debate atual sobre a formação em Psicologia no Brasil: permanências, rupturas e cooptaçôes nas politicas educacionais. (Tese de 
doutorado). Pontifícia Universidade Católica de São Paulo, Programa de Estudos Pós-Graduados em Psicologia Social, São Paulo.

Borges, M., Bastos, A. V. \& Khorui, I. A. (1995). A formação em Psicologia: contribuições para a reestruturação curricular e avaliação dos cursos. Brasília: Comissão de Especialistas de Ensino de Psicologia - MEC/SESU.

Botomé, S. P. (1979). A quem nós, psicólogos, servimos de fato? Psicologia, 5 (1), 1-15.

Brasil (1962). Currículo mínimo para os cursos de Psicologia. Brasília: Ministério da Educação. Recuperado a partir de http://www.abepsi.org.br/portal/wpcontent/uploads/2011/07/1962-curriculominimoparaoscursosdepsicologia. pdf

Brasil (2003). Normas para organização e realização de estágio de alunos do ensino médio e da educação profissional. Brasília: Conselho Nacional de Educação. Recuperado a partir de http://www.jusbrasil.com.br/diarios/49578707/ doemt-03-01-2013-pg-8.

Carvalho, A. M. (2002). Formação docente e afiliações grupais: implicações para a graduação em psicologia. Revista do Departamento de Psicologia da UFF, 14 (1), 109-119.

Cellard, A. (2008). A análise documental. In Poupart, J et al. A pesquisa qualitativa: enfoques epistemológicos e metodológicos. (pp. 295-316, A. C. Nasser, Trad.). Petrópolis: Vozes.

Coimbra, C. (1995). Guardiōes da ordem: uma viagem pelas práticas psi no Brasil do "milagre". Rio de Janeiro: Oficina do Autor.

Conselho Federal de Psicologia (1992). Carta de Serra Negra. Brasília: Conselho Federal de Psicologia. Recuperado a partir de http://www.abepsi.org.br/portal/ wp-content/uploads/2011/07/1992-cartadeserranegra.pdf

Conselho Federal de Psicologia (1994). Psicólogo brasileiro: práticas emergentes e desafios para a formação. São Paulo: Casa do Psicólogo.

Decreto no 87.497, de 18 de agosto de 1982.(1982, 19 de agosto). Regulamenta a Lei $\mathrm{n}^{\circ}$ 6.494, de 7 de dezembro de 1977, que dispóe sobre o estágio de estudantes de estabelecimentos de ensino superior e de $2^{\circ}$ grau e supletivo, nos limites que especifica e dá outras providências. Diário oficial da Uniāo. Recuperado a partir de http://www.planalto.gov.br/ccivil_03/Decreto/ D87497.htm 
Ferreira Neto, J. L. (2010). Uma genealogia da formação do psicólogo brasileiro. Memorandum, 18 (1), 130-142.

Ferreira Neto, J. L. (2011). Psicologia, políticas públicas e o SUS. São Paulo: Escuta.

Foucault, M. (1996). A ordem do discurso. (L. F. Sampaio, trad.). São Paulo: Loyola.

Francisco, A. L. \& Bastos, A. V. B. (1992). Conhecimento, formação e prática: o necessário caminho da integração. In A. L. Francisco, C. R. Klomfahs \& N. M. D. Rocha (Orgs.). Psicólogo brasileiro: construção de novos espaços. (pp. 211227). Brasília: Conselho Federal de Psicologia.

Gomes, W. B. (1996). Pesquisa e ensino em psicologia: articulações possíveis entre graduação e pós-graduação. In R. Carvalho. Repensando a formação do psicólogo: da informação à descoberta. (pp. 33-50). Campinas: Alínea. (Coletâneas da ANPEPP, 9).

Lei no 4.119, de 27 de agosto de 1962. (1962, 17 de dezembro). Dispõe sobre os cursos de formação em Psicologia e regulamenta a profissão de psicólogo. Diário Oficial da União. Recuperado a partir de http://www.planalto.gov.br/ ccivil_03/leis/1950-1969/L4119.htm

Lei $\mathrm{n}^{\circ}$. 5.692, de 11 de agosto de 1971. (1971, 12 de agosto). Fixa diretrizes e bases para o ensino de $1^{\circ}$ e $2^{\circ}$ graus, e dá outras providências. In São Paulo (Estado). Secretaria da Educação. Diretrizes e bases para o ensino de $1^{\circ}$ e $2^{\circ}$ graus. (pp. 5-14). São Paulo: IOE.

Lei no 6.494, de 7 de dezembro de 1977. (1977, 9 de dezembro). Dispóe sobre os estágios de estudantes de estabelecimento de ensino superior e ensino profissionalizante do $2^{\circ}$ grau e supletivo e dá outras providências. Diário Oficial da União. Recuperado a partir de http://www.planalto.gov.br/CCivil_03/leis/ L6494.htm

Parecer do CNE, n. 72/2002. (2002, 20 de fevereiro). Sobre as Diretrizes Curriculares - $2^{\text {a }}$ versão. Brasília: Ministério da Educação. Recuperado a partir de http://portal.mec.gov.br/cne/arquivos/pdf/2002/pces072_02.pdf

Parecer n. 403/62 do CFE. (1962, 19 de dezembro). Brasília: Ministério da Educação. Recuperado a partir de http://www.abepsi.org.br/portal/wpcontent/uploads/2011/07/1962-parecern403de19621.pdf. 
Pereira, S. L. (1975, maio). A formação profissional dos psicólogos: apontamentos para um texto. Psicologia, São Paulo, 1 (1), 15-20.

Resolução no 8, de 7 de maio de 2004.( 2004, 18 maio). Institui as Diretrizes Curriculares Nacionais para os Cursos de Graduação em Psicologia. Diário Oficial da União, Seção 1, 16-17, 18 maio 2004. Recuperado a partir de http:// portal.mec.gov.br/cne/arquivos/pdf/rces08_04.pdf

Rocha Júnior, A. (1999). Das discussões em torno da formação em psicologia às diretrizes curriculares. Psicologia: Teoria e Prática, 1 (2), 3-8.

Silva, M. R. (2008). Currículo e competências: a formação administrada. São Paulo: Cortez.

Weber, S. \& Carraher, T. N. (1982). Reforma curricular ou definição de diretrizes? Uma proposta para o curso de Psicologia. Psicologia, 8, 1-13. 